\title{
CONTROLE SOCIAL, PARTICIPAÇÃO POPULAR E SEUS DESAFIOS NO PROGRAMA NACIONAL DE ALIMENTAÇÃO ESCOLAR (PNAE): UMA ANÁLISE DOS CONSELHOS DE ALIMENTAÇÃO ESCOLAR (CAE) DE DOIS MUNICÍPIOS SERGIPANOS
}

\author{
SOCIAL CONTROL, POPULAR PARTICIPATION AND ITS CHALLENGES IN THE \\ NATIONAL SCHOOL FOOD PROGRAM (PNAE): AN ANALYSIS OF SCHOOL FOOD \\ ADVICE (CAE) OF TWO MUNICIPALITIES SERGIPANOS
}

\author{
Cristiane Souza Pinheiro ${ }^{1}$ \\ Cristiano Cassiano de Araújo ${ }^{2}$
}

\begin{abstract}
RESUMO: O presente artigo objetiva analisar o PNAE - Programa Nacional de Alimentação Escolar, por meio de uma discussão teórico-conceitual acerca das transformações desta política pública pela via do controle social. A principal hipótese refere-se à ruptura paradigmática do programa ao rescindir com os seus preceitos assistencialistas para se tornar uma política pública promotora de direitos. Para evidenciar o seu processo de transição, será analisado as ações do Conselho de Alimentação Escolar - CAE - em dois municípios sergipanos. Empregando uma metodologia qualitativa calcada em questionários e entrevistas semiestruturadas, realizadas nos anos de 2015 e 2016, conclui-se que tal instância deliberativa garante não somente a prática da cidadania com o envolvimento e acompanhamento dos (as) conselheiros (as) na execução do PNAE, como também legitima o controle social através do monitoramento desta política pública por meio do público assistido, consolidando a realização do direito à participação via controle social.
\end{abstract}

Palavras-chave: Controle Social, políticas públicas, alimentação escolar, promoção de direitos, cidadania.

\begin{abstract}
This article aims to analyze the PNAE - National School Feeding Program, through a theoretical-conceptual discussion about the transformations of this public policy through social control. The main hypothesis refers to the paradigmatic rupture of the program when it rescinds with its precepts of welfare to become a public policy that promotes rights. To demonstrate its transition process, the actions of the School Feeding Council - CAE - will be analyzed in two municipalities of Sergipe. Using a qualitative methodology based on questionnaires and semistructured interviews carried out in 2015 and 2016, it is concluded that such a deliberative body guarantees not only the practice of citizenship with the involvement and follow-up of the advisers in the implementation of the PNAE, but also legitimizes social control through the monitoring of this public policy through the assisted public, consolidating the realization of the right to participation through social control.
\end{abstract}

\footnotetext{
${ }^{1}$ Pós-Graduada em Contabilidade Gerencial (UFBA) e Gestão Pública (FCS); Agente PNAE-CECANE-UFBA, crissouzapinheiro@gmail.com

${ }^{2}$ Doutorando em Geografia (UFBA); Pesquisador do Grupo Território, Propriedade Intelectual e Patrimônio TERPI/UFBA cassianodearaujo@gmail.com
} 
Keywords: Social Control, public policies, school feeding, promotion of rights, citizenship.

\section{INTRODUÇÃO}

Tema muito em voga desde a promulgação da Constituição Federal de 1988 (CF/88), o conceito de controle social recebeu grande relevância nos últimos vinte anos no campo das ciências sociais, transformando-se em pauta das pesquisas deste e de outros campos interdisciplinares e figurando também nas agendas dos programas e políticas públicas brasileiras com o objetivo de efetivar a participação política de todos os cidadãos e cidadãs no seu âmbito institucional, mais precisamente, nas etapas de controle e fiscalização dos recursos públicos e de sua aplicabilidade. Para tanto, nessas últimas décadas, dois grandes desafios permeiam esta nova dinâmica política: encontrar os melhores instrumentos para a análise e avaliação destes mecanismos participativos, e a superação das tradições e concepções autoritárias que permeiam o arcabouço institucional brasileiro, principalmente na escala local, ou seja, nos municípios de pequeno porte que ainda são vítimas de tradições paternalistas e de outras práticas políticas não inclusivas. (LEAL, 1976).

Tendo em vista esta realidade, o presente artigo objetiva debater este contexto: os obstáculos, desafios e possibilidades na consolidação dessas práticas participativas e dos seus mecanismos de controle no ínterim do Programa Nacional de Alimentação Escolar (PNAE), mais precisamente, analisando as ações do Conselho de Alimentação Escolar (CAE), instância consultiva e deliberativa que legitima o controle social do programa. Embora a perspectiva amostral seja pequena, ou seja, serão analisados dois CAE em duas cidades do interior sergipano, este exercício, a nosso ver, será mais uma contribuição no intuito de compreender os percalços da participação do público assistido de um programa de governo no seu processo de fiscalização e monitoramento.

Assim, para referendar estas perspectivas, dividiremos o artigo em duas partes: a primeira trata de uma breve discussão teórico-conceitual sobre o conceito de controle social e o seu surgimento no arcabouço institucional do PNAE. A segunda refere-se à pesquisa de caráter qualitativo realizada com os CAE sergipanos.

\section{UMA SUCINTA CONTEXTUALIZAÇÃO SOBRE CONTROLE SOCIAL, PNAE E CAE}

Controle Social é a ação exercida de forma organizada, sistemática e individualizada pela sociedade civil sobre o Estado para o acompanhamento e a fiscalização das políticas públicas. Sua gênese perpassa pela descentralização administrativa proposta a partir do início dos anos 80, que 
influenciou reformas institucionais direcionadas para a descentralização das ações do Estado com enfoque no novo papel dos governos locais e na participação dos cidadãos na gestão da vida pública, seja em processos econômicos, políticos e administrativos (MASSOLO, 1988; SALLUM JUNIOR, 1994). Assim, pode-se considerar o controle social como um instrumento facilitador de Políticas Públicas, fortalecendo a sociedade civil por meio de uma nova forma de gerenciar as contas públicas, adequando-as às exigências legais e dando-lhes transparência.

Criado no ano de 2001 sob esses princípios, o Conselho de Alimentação Escolar (CAE) é um colegiado permanente, deliberativo e autônomo, que tem como atribuições físcalizar a aplicação dos recursos transferidos pelo Fundo Nacional de Desenvolvimento da Educação (FNDE) às prefeituras e estados e relatando os casos de irregularidades neste processo. Cabe ainda ao conselho, zelar pela qualidade dos produtos desde a compra até a oferta da alimentação aos alunos, observando, igualmente, as práticas sanitárias e de higiene envolvidas no preparo da merenda. Para melhor compreender o trabalho do Controle Social na gestão do PNAE pela via do CAE, é indispensável conhecer três legislações que o fundamentam: a Medida Provisória $n^{\text {o }}$ 2178-36 de 2001, a Lei 11.947/2009 e a Resolução do FNDE n. 38/2009, esta última traz resumidamente as principais diretrizes do CAE, por isso, como faremos uma breve discussão a respeito daquelas características mais importantes para o debate que se segue, iniciaremos a partir do seu Art. 26 que estabelece a composição dos membros do conselho:

"I - Um representante indicado pelo Poder Executivo (que não pode ser o ordenador de despesas);

II - Dois representantes dentre as entidades de docentes, discentes ou trabalhadores da educação, sendo usualmente escolhidos os professores;

III - Dois representantes de pais de alunos;

IV - Dois representantes indicados por entidades civis organizadas." (Resolução FNDE nº. $38 / 2009$ )

O segundo elemento a ser evidenciado refere-se ao Art. 27 da mesma Resolução, que estabelece as suas atribuições:

"I - Acompanhar e fiscalizar o cumprimento do disposto nos arts. $2^{\circ}$ e $3^{\circ}$ desta Resolução (princípios e diretrizes do PNAE);

II - Acompanhar e fiscalizar a aplicação dos recursos destinados à alimentação escolar;

III - Zelar pela qualidade dos alimentos, em especial quanto às condições higiênicas, bem como à aceitabilidade dos cardápios oferecidos; e

IV - Receber o Relatório Anual de Gestão do PNAE, conforme art. 34 e emitir parecer conclusivo acerca da aprovação ou não da execução do Programa." (Resolução FNDE nº 38/2009).

$\mathrm{O} \S 2^{\circ}$ do mesmo artigo traz ainda as competências do CAE:

"I - A obrigatoriedade de comunicar aos órgãos de controle, em especial o FNDE, Tribunais de Contas, CGU e Ministério Público qualquer irregularidade identificada na execução do PNAE;

II - Fornecer informações e apresentar relatórios sobre o acompanhamento do PNAE sempre que solicitado; 
III - Realizar reunião específica para apreciação da prestação de contas com a participação de, no mínimo, 2/3 (dois terços) dos conselheiros titulares;

IV - Elaborar o Regimento Interno, observando o disposto nesta Resolução." (Resolução FNDE n'. 38/2009).

Analisando os atributos e perfil do CAE, os mesmos encontram-se em consonância com a legislação que reformulou o PNAE, a Lei 11.947/2009, esta lei, define o repasse de recursos financeiros diretamente aos Estados, Distrito Federal, Municípios e Escolas Federais em caráter complementar, destinando esses recursos exclusivamente à aquisição dos produtos necessários para a alimentação escolar. Para este procedimento ser realizado, o texto jurídico exige a inserção de um mecanismo fiscalizador na gestão deste processo, o que corrobora dois pontos de vista: primeiro, que o PNAE, por meio do CAE, efetiva a participação popular ao instituir o conselho e nomear os (as) conselheiros (as) que irão representar a sociedade civil, materializando-os através das normas legais; segundo, esta dinâmica contribui para a inovação do atual modelo de gestão ao delegar o conselho como a instância de coordenação dessas transferências de recursos do FNDE aos cofres municipais, auxiliando, diretamente, o planejamento das aquisições dos gêneros alimentícios e assegurando a oferta da alimentação escolar durante todo o ano letivo.

Embora mereça uma análise mais pormenorizada, o conceito de controle social não será aqui estendido, o que se propôs neste momento foi fazer uma breve conceituação do tema e uma sutil associação dos seus preceitos àquelas diretrizes que fundamentam a criação e operação do CAE. No entanto, para discutir os conflitos, obstáculos, desafios e possibilidades de acerto desses fundamentos, apresentaremos as entrevistas realizadas com os CAE sergipanos, onde lançaremos um olhar para esses conflitos através de três elementos presentes na literatura sobre os conselhos de políticas públicas (TATAGIBA, 2002; BRONZO, 2003) que, por sinal, explicitam o percurso metodológico de tal análise.

\section{PESQUiSA QUALITATIVA DESENVOLVIDA JUNTO A DOIS CONSELHOS DE ALIMENTAÇÃo ESCOLAR DO ESTAdo DE SERGIPE: UM PERCURSO METODOLÓGICO.}

O estudo ao qual iremos a partir de agora nos referendar segue um percurso metodológico que é fruto da continuidade de uma pesquisa acadêmica, onde a tutela e o aporte teórico das concepções trazidas pelas ciências sociais, mais especificamente pela ciência política e seus instrumentos de análise, balizam não somente o seu referencial teórico como também possui enquanto objetivo o seu tratamento empírico por meio da tentativa de materializar concretamente os caminhos percorridos pelos CAE no que tange aos seus obstáculos, desafios e possibilidades em se 
tornar um mecanismo de colaboração funcional que influencie o controle sobre o exercício da política em questão, ou seja, o PNAE.

Durante os quatro meses de elaboração, desenvolvimento, trabalho de campo e análise dos dados desta pesquisa, muitas indagações foram feitas para que o questionário desenvolvido pudesse, por meio das especificidades, minucias e singularidades oferecidas pela pesquisa qualitativa na extração de informações advindas da realidade social, absorver as principais características das formas de deliberação tomadas pelos CAE no dia a dia da gestão do PNAE. Para tanto, optou-se aqui em utilizar os pressupostos da análise do processo decisório, campo analítico da ciência política que se refere às formas de análise acerca da condução de um determinado processo de decisões e dos mecanismos utilizados por empresas ou governos para garantir a eficácia e eficiência dos mesmos, levando em conta os atores que fazem parte deste processo decisório e as diversas contribuições dos arranjos políticos e institucionais ao procedimento como um todo. (PEREZ, 2004).

Destarte, a metodologia teve como etapa preponderante a revisão bibliográfica a respeito do tema Conselhos de Políticas Públicas. Nela, encontra-se duas outras pesquisas realizadas no início dos anos 2000, a primeira, desenvolvida pela professora da UNICAMP, Luciana Tatagiba (2002), intitulada "Os conselhos gestores e a democratização das políticas públicas no Brasil”, e a segunda, desenvolvida pela professora e pesquisadora da Fundação João Pinheiro (MG), Carla Bronzo (2003), intitulada "Conselhos de políticas públicas: desafios para sua institucionalização", ambas constituem a base das discussões.

Esses três estudos foram de suma importância, pois traziam as metodologias e pesquisas qualitativas como contribuição teórica. A importância desta matriz metodológica reside no fato de que as pesquisas qualitativas são diretrizes científicas que visam à busca pela profundidade de um respectivo objeto, trabalhando valores, crenças, opiniões, atitudes e representações, partindo do todo para o particular no intuito de formular pressupostos que permitam encaminhar a investigação empírica do tema proposto. (MINAYO, 2003).

Não obstante, para encaminhar uma investigação empírica de questões de cunho teórico é necessário ter em mente o que se quer e o que se pretende com o material colhido e compilado, isto é, quais informações se deseja elencar e qual será o seu tratamento. Dessa forma, elaborou-se um questionário para entrevistas semiestruturadas, esta categoria combina perguntas fechadas e abertas onde o entrevistado tem a possibilidade de discorrer sobre o tema proposto. Uma das vantagens 
deste método diz respeito à sua elasticidade quanto à duração, permitindo uma cobertura mais profunda sobre determinados assuntos. (MANZINI, 2004).

Todavia, era necessário decidir o número amostral da pesquisa. Sabendo-se que os CAE são compostos por sete conselheiros e outros sete suplentes, ou seja, quatorze no total, optou-se por entrevistar três conselheiros (as) de cada um. Esse número de entrevistados, três, teve um motivo: ao observar o paritarismo proposto pela Resolução FNDE N. ${ }^{\circ}$ 38/2009, a mesma exige que o conselho possua apenas um (a) conselheiro (a) governamental, dois representante dos pais de alunos, dois das organizações da sociedade civil e dois representantes das entidades docentes.

Assim, decidiu-se que seria entrevistado um membro governamental, um representante das entidades docentes e um conselheiro (a) indicado (a) pelas organizações da sociedade civil $^{3}$.

Assim, ao se decidir por três membros, por questões éticas, não serão revelados os nomes dos municípios e nem a identidade dos conselheiros e das conselheiras. Para facilitar ao leitor, dividiu-se a Cidade 1 com a Conselheira A (não governamental - docente), Conselheiro B (governamental) e Conselheira C (não governamental - sociedade civil); e a Cidade 2, com a Conselheira D (governamental), Conselheiro E (não governamental - docente) e Conselheiro F (não governamental - sociedade civil). Portanto, tendo em vista a limitação de páginas aqui concedidas, não será debatido todos os temas investigados pela pesquisa, serão examinados apenas três elementos importantes para a sua discussão, são eles: a associação do conceito de controle social ao conceito de accountability; o CAE enquanto espaço de argumentação e deliberação; e o desempenho institucional do conselho em relação ao cumprimento das diretrizes legais referentes aos $30 \%$ da alimentação escolar ofertada pela agricultura familiar ${ }^{4}$.

a) Controle social e accountability: para além da deliberação

Analisando a importância do controle social na estrutura do PNAE, é importante que os conselheiros e as conselheiras tenham em mente que o seu papel nada mais é do que ser os representantes da sociedade civil no ínterim deste controle. Sendo assim, o que eles sabem sobre controle social? A nosso ver, a importância da assimilação deste conceito sob a perspectiva da análise dos processos decisórios, é tão crucial quanto saber o que é e para que serve um (a) conselheiro (a). Por isso, deu-se início ao questionário com a seguinte pergunta: "Defina com suas

\footnotetext{
${ }^{3}$ Nenhum dos conselhos pesquisados apresentou representantes dos pais de alunos.

${ }^{4}$ Lei 11.947/09. Art. 14. "Do total dos recursos financeiros repassados pelo FNDE, no âmbito do PNAE, no mínimo $30 \%$ (trinta por cento) deverão ser utilizados na aquisição de gêneros alimentícios diretamente da agricultura familiar e do empreendedor familiar rural ou de suas organizações, priorizando-se os assentamentos da reforma agrária, as comunidades tradicionais indígenas e comunidades quilombolas."
} 
palavras, o conceito ou o sentido de Controle Social da Alimentação Escolar ou PNAE.” Vejamos o que esses e essas representantes da sociedade civil entendem por controle social.

Já ouvi falar do controle sim, é que vem o dinheiro e não é toda a qualidade de merenda que pode ser comprada, daí vem a nutricionista, a nutricionista é quem vai avaliar o que as crianças precisa se alimentar. Bom... então eu entendo isso aí, dessa forma (Conselheira A não governamental do CAE, Cidade 1).

Ok. Bom, pelo meu conhecimento, né?, a respeito do Programa Nacional de Alimentação Escolar, é um programa do governo federal, né?, que visa o repasse da merenda escolar para todos os municípios do Brasil. É um programa fiscalizador que faz parte também do controle de toda a merenda no território nacional, brasileiro, no caso. (Conselheiro B governamental do CAE, Cidade 1).

Eu defino assim... como um órgão que está aí pra ajudar os municípios na questão da alimentação escolar... é... eu vejo dessa forma (Conselheira D governamental do CAE, Cidade 2).

Controle social seria... é... seria uma intervenção desde a aquisição, quando a verba chega, até o momento em que a criança recebe o alimento ali, na unidade escolar. Aí vem a questão da licitação, participação e observação aos preços, ao cardápio; também na questão da fiscalização, da prestação de contas, observar o armazenamento; também, como está sendo servido, como está sendo preparado pela comunidade escolar... é muito importante esse controle. (...) Muitos pais observam e fala pra gente, isso é muito bom! Deveria mais, né? Deveria participar mais, não só aquele que está investido como conselheiro, mas também aquele pai que visita a unidade escolar e observar também o que o filho fala em casa como é a merenda; se o filho está passando fome, se o filho dele está tendo alimentação, né? Por que o filho dele não tá querendo aquela alimentação da escola (...) isso é um processo, porque os pais não estão educados para esta intervenção, né? E a participação ainda é pouca, são poucos pais que chegam a dizer, a questionar a merenda, muito pouco (Conselheiro F não governamental do CAE, Cidade 2).

Neste caso, o controle social é facilmente associado à palavra inglesa accountability, muito utilizada pelas ciências sociais e administrativas para definir os instrumentos das agências estatais que supervisionam rotinas de todos os trâmites que envolvem uma empresa ou governo na instituição de instrumentos para o controle e a prestação de contas públicas. (BRAVO; CORREIA, 2012). Dessa forma, compreendem-se as respostas acima, pois, com exceção do conselheiro $F$, que elaborou um pouco melhor a sua resposta, os demais tinham apenas conhecimentos esparsos a respeito do conceito. Não nos interessa aqui julgar as respostas, mas compreendê-las: a associação entre controle social e fiscalização é salutar, pois é uma das suas diretrizes, entretanto, é importante observar que o controle social apreendido por um conselho como o CAE é também um instrumento pedagógico. (TATAGIBA, 2002; BRONZO, 2003; ALVAREZ, 2004).

Portanto, ao comparar as três primeiras respostas com a última, nota-se uma compreensão diferente do Conselheiro F em relação ao controle social, pois suas ideias perpassam desde a chegada da merenda à mesa do escolar ao processo de participação e fiscalização do alimento licitado, seu preparo, armazenamento e prestação de contas. Mas um trecho de sua fala também assimila outra face do controle social, quando ele fala da presença do pai, "fiscalizando" o seu filho 
ao querer saber como está a merenda na escola e se dirigindo a escola para tomar detalhes desta mesma merenda; e claro, a necessidade de se ter mais pessoas neste processo mobilizatório. E foi justamente esta outra assimilação do conceito de controle social que achamos interessante: a atmosfera da participação que gera, antes de tudo, este processo mobilizatório no âmago de uma causa, neste caso, a merenda escolar.

b) O CAE: espaço de argumentação x espaço de deliberação.

Teoricamente, os conselhos são canais de participação política onde o controle público sobre a ação governamental não somente legaliza a sua institucionalização, mas também dá publicidade às suas ações e às ações governamentais. Este espaço de formação insere-se na agenda governamental junto às demandas de interesse público, tornando efetivas a formação de consensos e a construção de social num universo coletivo.

No entanto, como discutido por Bronzo (2003) a respeito da composição dos conselhos, e no caso dos CAE analisados, esses espaços de argumentação sofrem influências que, dentre outras variáveis, podem transformá-los em lócus da deliberação governamental, dependendo do interesse do poder público. Além do mais, o que se percebeu é que o poder de deliberar o que foi colocado em pauta torna-se um dos grandes desafios do CAE, principalmente em relação à burocracia que permeia o debate de suas demandas e que exerce grande influência ao torna-las exequíveis, ou não. É aí que entra a importância do gestor, pois essas burocracias podem ser facilitadas ou não pelo poder público, podendo dar agilidade às questões demandadas pelo CAE ou até mesmo fornecer obstáculos às mesmas.

Para absorver tal situação e trazê-la ao debate, perguntou-se aos conselheiros (as) entrevistados (as): "Quanto à relação do CAE com a Prefeitura e demais órgãos públicos, o conselho possui a capacidade de deliberar, controlar e fazer cumprir suas decisões? Quais os principais desafios políticos e institucionais hoje existentes que impedem, atrapalham ou atrasam as ações do CAE?" Algumas respostas auxiliarão o debate, vejamos.

Olha, das ações que impedem, vai depender do gestor público... o Prefeito, né? Pelo menos o presidente [do CAE] que sempre tá lá, tem uma boa relação. Até agora, nesta gestão, nós não tivemos problemas com a deliberação, mas eu acho que nós temos capacidade, sim, porque se o gestor não ouvir nosso lado - da gente que está no CAE - a gente vai partir pra denúncia, né? (...) As burocracia, no caso, é muita coisa, quando diz assim, se realmente não precisasse de cooperativa para comprar os alimentos aqui, nós comprava tudo aqui, é claro, né? Vamos valorizar a nossa terra! Isso já é uma burocracia que atrasa muito, porque a gente tá comprando em outra cidade, em vez de valorizar o pessoal daqui... existe essas burocracias que atrapalham, se não existisse isso seria muito mais fácil a gente comprar aqui, os alimentos da nossa terra: macaxeira, a laranja, a banana, as frutas que tem na nossa terra, era mais fácil, se não fosse essa burocracia de exigir a cooperativa. Porque são muitas 
as burocracias que existe, mas no fundo, essas burocracia são para fiscalizar, nota fiscal e essas coisas, eu entendo. Agora vamos ao outro lado político: no caso de uma pessoa que faz parte, um gestor da oposição é mais difícil conversar com o Prefeito, porque é por senha hoje em dia, isso se torna muito difícil... é mais fácil o pessoal deles... (Conselheira A, não governamental, Cidade 1).

A relação com o CAE, hoje, é boa, o secretário tem ajudado muito, pois a última gestão você sabe, né?, deixou a desejar. Quanto ao desafio institucional, o grande problema foi a gestão anterior, e as documentações que não temos dela, isso está atrapalhando o nosso desenvolvimento. Quanto ao desafio político, aqui é muito determinado nas pessoas, situação e oposição, aí eu acho que isso conta muito, pois quando você tem aquela mentalidade de que eu só vou seguir esse caminho, que eu só quero esse caminho, fica difícil trabalhar, porque mesmo você fazendo certo, mesmo você tendo a intensão, você é visto como... não é do X... então é... é... é doido! Essa é a dificuldade política (...) mas, com o tempo, quem sabe, a gente não chega numa situação de equilíbrio, igualitária (Conselheiro B governamental do CAE, Cidade 1).

Nota-se com facilidade nas declarações a preocupação dos (as) conselheiros (as) com o gestor, isto porque, o grau de importância que o mesmo tem para as decisões tomadas, influenciam diretamente a materialização destas, e caso essas decisões não se concretizem de certa forma, enfraquece o processo de argumentação que um espaço como o CAE objetiva proporcionar. Entretanto, além da influência direta no processo de argumentação ensejado pelo conselho, este, por sua vez, torna-se dependente também da eficiência do controle exercido pelo próprio Estado - leiase poder público - (BRONZO, 2003), e é aí que o Estado pode melhorar ou atrapalhar os processos argumentativos e deliberativos, pois os mesmos dependerão tanto dos interesses do gestor quanto da capacidade e eficácia do governo municipal. A nosso ver, os fragmentos dos conselheiros do segundo município corroboram tais perspectivas.

Deliberar, até que nós temos o poder, mas... as grande melhoria que a gente tem tentado buscar para os âmbitos escolares, na questão do próprio refeitório, como o CECANE colocou, esbarra na burocracia do país... porque cria a licitação pra ser transparente, mas a licitação só faz atrapalhar os trabalhos... que passa seis meses para acontecer uma licitação, e a gente naquela ânsia de ver as coisas acontecerem, ficamos revoltados. Então, deliberar, nós temos o poder de deliberar, mas na hora da execução dessas deliberações, é onde as coisas se emperram (...) a licitação, por exemplo, é um desafio do CAE, tanto político quanto institucional. (Conselheiro E não governamental do CAE, Cidade 2)

Não é de agora que a gente coloca isso, há anos que a gente coloca isso com as administrações anteriores e não vem sendo executado. A gente tem essa aqui, oh: como o Plano de Ação, né?, que a gente colocou tudo o que a gente vê que necessita, muitas coisas foram feitas, mas eu acho que não ultrapassou os cinquenta por cento, né? Aí, é assim... deliberar a gente delibera, agora, que eles cumpram, vai depender da vontade política. (Conselheiro F não governamental do CAE, Cidade 2)

Preocupada com a dimensão que tal contexto pode tomar no âmbito das políticas públicas, Cunil Grau (2000) discute sobre a institucionalização das instâncias de mediação da sociedade (leiase, conselhos) e o seu grau de dependência do Estado para se efetivar. Trazendo para o nosso caso, este paradoxo, autonomia do conselho $\mathrm{x}$ influência do poder público, encontra-se em vigor nas palavras dos (as) entrevistados (as), uma vez que todos (as) apresentam as dificuldades existentes 
para que o poder público compreenda e aceite a participação daqueles conselheiros e conselheiras que, fazendo ou não parte do seu arranjo de forças, consolidam este processo de argumentação e discussão das demandas da alimentação escolar, que pode ser desvirtuado pelo poder público no processo de deliberação. Dessa forma, indaga-se: como ultrapassar esse paradoxo?

$\mathrm{O}$ contexto aqui narrado faz parte não somente do dia a dia dos CAE em questão, mas encontra-se na literatura sobre o tema como um dos principais elementos que travam as iniciativas dos conselhos de uma forma geral, ou seja, o controle do poder público sobre a agenda temática dos conselhos e as dificuldades daquele na partilha do poder de decisão (deliberação).

c) Desempenho institucional: o cumprimento das diretrizes legais em relação aos $30 \%$ da agricultura familiar.

O cumprimento das diretrizes legais de um conselho se efetiva quando o mesmo possibilita eixos de atuação. Segundo Bronzo (2003), esses eixos podem ser divididos em dois: as ações executadas e as prioridades do conselho. No caso dos CAE analisados, em relação às prioridades, optou-se por examinar a contribuição do conselheiro ou da conselheira na mudança da alimentação escolar para melhor; já as ações executadas, elegeu-se o fato dos mesmos conseguirem, ou não, exigir os $30 \%$ da alimentação escolar advindos da agricultura familiar. As respostas por si nos dão a dimensão do desempenho institucional dos CAE. Antes, porém, segue a pergunta dirigida aos (as) conselheiros (as): "Você pode mudar a alimentação escolar para melhor? Pode exigir os 30\% da alimentação escolar vinda da Agricultura Familiar?”.

Nós podemos mudar a alimentação pra melhor sim, junto com a nutricionista, né? Mas também vai depender do valor do dinheiro que entra no município; como é que a gente vai mudar se o dinheiro é pouco? Não tem como. Vai depender do valor do dinheiro pra mudar a alimentação. Precisamos de mais dinheiro (risos). Aí vai depender do gestor, se vai liberar ou não. Nutricionista nós temos, (...) nas nossas reuniões a nutricionista sempre participa, explica como vai ser a merenda, tantas calorias (...) tem quem vê a saúde da criança. Nós podemos exigir os trinta por cento da agricultura familiar, a nutricionista já tem tudo, aqui na região, só foi conseguido pessoas que vende da agricultura... como não tem inhame, macaxeira, laranja, essas coisas... aqui não tem. Aí, ela conseguiu... eu não lembro agora, não sei se foi em Frei Paulo, Lagarto, tem que ir num lugar melhor, a cidade produz, mas na verdade tá faltando vê se ele é - como é que se diz... tem que ter uma empresa, no caso. Cooperativa! Aqui não tem! Por isso que não compra dos agricultores daqui. (...) Nós já conversamo muito, já buscou em outras cidades, eu não sei se foi Moita Bonita ou se foi Malhador, Lagarto e Frei Paulo; acho que é esses aí, um dos três, porque ela trabalha em outros lugares como nutricionista, em outras cidades, e ela já tem os dados, e já aqui, não tem, por isso que realmente não é comprado aqui. (Conselheira A não governamental do CAE, Cidade 1).

Essa questão é que no município, aqui, não tem condições desses trinta por cento ser exigido, município pequeno de agricultura de subsistência, não tem exportação desses... agricultura... aí eu acho que fica difícil. Mas eu acho que com uma boa... um bom diálogo, né?, com projetos, com planos, eu acho que isso poderá ser viabilizado dentro de algum tempo. Eu acho que com planejamento, com projetos visando isso, poderá, logo-logo ter 
seus trinta por cento vindo daqui mesmo, do nosso povo, né? (Conselheiro B governamental do CAE, Cidade 1).

Analisando o discurso dos dois primeiros conselheiros, nota-se uma diferença de interpretação, principalmente nas ações executadas. De acordo com a primeira conselheira, existe, sim, agricultura familiar, o problema da exigência paira justamente na falta de cooperativas com DAP para a comercialização de seus produtos junto às escolas do município ${ }^{5}$; já em relação às prioridades, de acordo com a mesma, eles conseguem mudar a merenda para melhor, e, diga-se de passagem, com o auxílio da nutricionista.

O segundo conselheiro, governamental, traz no seu discurso uma conotação clara de dúvidas. De acordo com o mesmo, a agricultura local é de subsistência, não tem exportação dos alimentos da agricultura, isto é, não são comercialmente atraentes. O mesmo conselheiro não analisou as prioridades, o que nos faz questionar até que ponto ele tem conhecimento das mesmas. Além do mais, seu discurso institucional deixa claras as pretensões futuras do poder público: com diálogo, com planos, projetos. Daí questiona-se: em relação ao desenvolvimento institucional do CAE, por meio de qual discurso pode-se saber o que está acontecendo e em que medida as ações executadas e as prioridades estão sendo tratadas? Para completar essa análise, observemos os próximos fragmentos.

O CAE é uma pedra no sapato do poder público. Porque vira moda, nós estamos cobrando, e essa cobrança você sabe que causa um... desconforto - e ninguém quer sair da sua zona de conforto. Até o cardápio, quando ele é elaborado pela nutricionista, ele tem que passar pelo conselho, através do teste de aceitabilidade. Podemos cobrar sim [30\% da agricultura familiar], o trabalho que eles fazem é muito bom com a agricultura familiar. A gente nem precisa, assim... com a cobrança, porque já é de lá mesmo, já vem definido, e a gente acompanha. (Conselheira D governamental do CAE, Cidade 2).

O que é que acontece aqui: muitas das pessoas não têm terra, trabalha em terra de parente em sistema de comodato, não tem condições de comprar uma área de terra pra tá produzindo em massa. Então, se a Prefeitura pudesse tá comprando uma área de terra num local onde tivesse bastante água pra colocar um sistema de irrigação, e tá botando aquelas pessoas que realmente querem produzir e pra melhorar de vida com o seu trabalho, o plano daria mais certo, porque o nosso município não produz cenoura, e se plantar a batatinha, se plantar dá. Agora, tem que ter uma área que tem água, e isso não tem, essa é a grande questão. Não tem água irrigável. O que a gente planta é com sacrifício, é tirando água do poço pra tá aguando, entendeu? Aí, o capital que tinha pra investir na plantação, teve que usar pra cavar um poço (...) quando tem chuva não há problema nenhum, mas quando o verão bate... os poços tende a secar e a produção cai muito. E outra questão que tem na dificuldade da produção, é uma praga que tem, o tal do caramujo africano, o caramujo africano, hoje, se você não tiver atento, vai embora toda a sua produção, ele come. (...) Aí o poder público, essa semana, a Secretária de Saúde tava dizendo que esse problema tava sanado, aí você vê que ela não tem andado no município. (...) Quando você tenta intervir nesta questão [agricultura familiar], e se você bate de frente de pessoas que tem comprador, é... a mercadoria em outros municípios pra tá botando aqui, e quando a gente vai bater contra isso, aí a gente é mal visto. Aquele papel do político colocar você como adversário do

\footnotetext{
${ }^{5}$ DAP - Declaração de Aptidão do PRONAF é utilizada como instrumento de identificação do agricultor familiar para acessar políticas públicas, como por exemplo, o Programa Nacional de Fortalecimento a Agricultura Familiar PRONAF. Para obtê-la, o agricultor (a) familiar e seu cônjuge (se possuir) deverão dirigir-se a um órgão ou entidade credenciada pelo MDA
} 
agricultor, tá entendendo? (...) Então, é um grande problema que a gente tem, se a gente fiscaliza e bota, pega o pé, você é mal visto, porque o cara não vai deixar de receber o dinheiro, porque foi você é quem indicou que ele não tinha mercadoria e tava comprando em outro município ou de terceiros. (Conselheiro $\mathrm{E}$ não governamental do $\mathrm{CAE}$, Cidade 2)

Neste caso, o discurso dos conselheiros se encontram com mais facilidades de interpretação em relação aos conselheiros da Cidade 1, isto porque, na Cidade 2, existe um programa de apoio à agricultura familiar. Contudo, ainda existem diferenças nos discursos, e essas diferenças têm relação com a posição ocupada por cada conselheiro. Como dito anteriormente, a primeira conselheira é indicada pelo poder público, já o segundo conselheiro, além de ter sido eleito pela sociedade civil, foi indicado pelo Sindicato dos Trabalhadores Rurais de seu município, por isso, nos ateremos em sua fala.

O discurso do Conselheiro E traz uma fala de quem realmente conhece o que está dizendo e sabe com o quê está lidando. Além do mais, ele deixa claro os problemas que envolvem os $30 \%$ da agricultura familiar no município: a questão do atravessador. Intrinsicamente, o Conselheiro E demonstrou que por maior que sejam os investimentos que o município destina à agricultura familiar, eles ainda são poucos em relação ao poderio dos atravessadores. A questão da terra no seu discurso é crucial, pois, sem ela, e sem o seu pertencimento ao núcleo familiar, não existe agricultura familiar, pois os dividendos desta modalidade, se não são divididos entre os membros da família, são repassados para o dono da terra onde os agricultores familiares encontram-se como meeiros. Além do mais, outro problema apontado refere-se às pragas existentes que atrapalham a produção e, consequentemente, a qualidade do alimento produzido. Portanto, fica evidente que o CAE, quando constituído de pessoas que dominam os seus assuntos e diretrizes, pode, acima de tudo, ser um mecanismo de articulação política junto às Secretarias de Agricultura dos municípios, corroborando as perspectivas acerca da intersetorialidade, melhorando, consequentemente, o seu desempenho institucional, um dos grandes problemas enfrentados pelos conselhos de uma forma geral. (TATAGIBA, 2002; BRONZO, 2003; ALVAREZ, 2004; BRAVO; CORREIA, 2012; MACIEL, 2010).

\section{CONSIDERAÇÕES FINAIS: LONGE DE FINALIZAR AS CONSIDERAÇÕES.}

Como observado, os conselhos de políticas públicas são espaços onde a sociedade civil e o poder do Estado se encontram para efetivar políticas e programas que deem conta de suas demandas. Tendo como base a literatura a respeito do tema, esses são espaços tanto para se exercer a fiscalização quanto para proporcionar pedagogicamente aos seus usuários uma atmosfera democrática em relação a um direito constitucional, ou seja, o da participação popular no âmbito da 
concepção, planejamento, implementação e controle/fiscalização de uma respectiva política pública; tudo isso, permeado pelo diálogo e pela busca do consenso.

Assim, no caso dos CAE em destaque, embora o conceito de controle social não tenha sido tão bem formulado por seus participantes, percebeu-se que as suas diretrizes, intrinsicamente, estão absorvidas pelos mesmos, que as assentam à frente do conselho e que procuram da melhor forma possível coloca-las em prática para a gestão do programa. O CAE, enquanto mecanismo de accountability é um instrumento que funciona: isso é fato!

Quanto à inserção institucional e eficácia deliberativa, esta questão é crucial para a efetividade do trabalho de um conselho. Em que medida a inserção institucional dos conselheiros e conselheiras garante a sua eficácia deliberativa? É necessário ter mais conselheiros (as) ligados à situação política do município do que aqueles e aquelas que são oposição a atual gestão? Essas duas perguntas são inspiradas nas frases e diálogos dos (as) conselheiros (as), pois, a todo o momento, essa questão foi alvo do debate: conselheiros (as) governamentais e não governamentais deixaram claro que suas opiniões podem ou não ter mais peso dependendo do arranjo de forças políticas que ali vigora.

Portanto, outro debate que não cessa e que deve ser alvo de novas investigações diz respeito a este poder institucional e sua influência não somente na eficácia deliberativa, mas também na questão da participação do poder público nos conselhos, ou seja, dos seus conselheiros governamentais que carregam com si os interesses da Prefeitura, e o caso dos 30\% para a agricultura familiar é emblemático. A importância deste exame recai sobre outros elementos para se analisar a atuação dos CAE, como por exemplo, os instrumentos para efetivar a dimensão normativa e deliberativa dos conselhos. Aqui, retornamos a frase do Conselheiro F, não governamental, Cidade 2, quando ele deixa claro que “(...) deliberar a gente delibera, agora, que eles cumpram, vai depender da vontade política." Neste caso, este discurso questiona duas fases de suma importância para o trabalho do CAE, quais sejam: a autonomia e a efetividade do poder de decisão dos conselhos (BRONZO, 2003).

As diretrizes trazidas pela Resolução N. ${ }^{\circ}$ 38/2009 demonstram que no seu desenho institucional o FNDE procurou deixar o conselho o mais paritário possível, não obstante, percebe-se nas falas dos conselheiros e das conselheiras a grande influência das Prefeituras, que, mesmo em menor número, possui na efetivação dos assuntos tratados pelos CAE, não somente esta influência, mas transparece que o poder público consegue, politicamente, coordenar algumas decisões. Como 
já assinalado por diversos autores (TATAGIBA, 2002; BRONZO, 2003; ALVAREZ, 2004; BRAVO; CORREIA, 2012; MACIEL, 2010), isso demonstra a força do poder público nas decisões dos conselhos, e, de uma forma discreta, a limitação da autonomia dos conselhos ao usar tal influência nas direções tomadas pelos mesmos.

Esse é um dos principais perigos apontados em outros estudos neste campo do conhecimento (TATAGIBA, 2002; BRONZO, 2002; GOMES, 2003), e para alguns autores, o mais temível: a transformação desses espaços em lócus da deliberação governamental, passando por cima da autonomia conselhista e minando a efetividade do seu poder de decisão ou atrelando-a aos interesses do poder público e dos arranjos políticos em voga.

\section{BIBLIOGRAFIA}

ALVAREZ, M. C. 2004. Controle social: notas em torno de uma noção polêmica. São Paulo em Perspectiva, São Paulo, v. 18, n.1, p. 168-176, Jan./Mar. 2004.

BRASIL. Resolução FNDE Nº 38, de 16 de junho de 2009.

BRASIL. Lei 11.947/2009, de 16 de junho de 2009.

BRAVO, M. I. S.; CORREIA, M. V. C. 2012. Desafios do controle social na atualidade. Serviço Social \& Sociedade, São Paulo, s/v, n. 109, p. 126-150, Jan./Mar. 2012.

BRONZO, C. 2002. Conselhos de Políticas Públicas: desafios para sua institucionalização. RAP Revista Brasileira de Administração Pública, Rio de Janeiro, v. 36, n.2, p. 277-292, Mar./Abr. 2002.

DAGNinO, E. (Org.). 2002. Sociedade Civil e Espaços Públicos no Brasil. São Paulo: Paz e Terra, 2002.

LEAL, V. N. 1976. Coronelismo, enxada e voto: o município e o regime representativo no Brasil. 3. ed. São Paulo: Alfa-Omega.

MACIEL, C. A. B. 2010. Políticas Públicas e Controle Social: encontros e desencontros da experiência brasileira. Disponível em: <http://www.uniblog.com.br/espgestaoemsaude/485175/politicas-publicas-e-controle-social-encontros-e-desencontros-daexperiencia-brasileira.html>. Data de acesso: 22 de março de 2017.

MANZINI, E. J. Entrevista semi-estruturada: análise de objetivos e de roteiros. In: SEMINÁRIO INTERNACIONAL SOBRE PESQUISA E ESTUDOS QUALITATIVOS, 2004, Bauru. Anais. Bauru: USC, 2004, p. 1-10.

MASSOLO, A. 1986. Em direção às bases: descentralização e município. Espaço \& Debate, São Paulo, v.8, n.24, p.40-54, Abr. 1988. 
MINAYO, M. C. de S. (Org.). 2003. Pesquisa social: teoria, método e criatividade. 22 ed. Rio de Janeiro: Vozes.

PEREZ, M. A. 2004. A Administração pública democrática: institutos de participação popular na Administração Pública. Belo Horizonte: Editora Fórum.

SALLUM JUNIOR, B. 1994. Transição Política e Crise de Estado. Lua Nova, São Paulo, s/v, n³2, p.133-167, Abr. 1994.

TATAGIBA, L. Os Conselhos Gestores e a democratização das políticas públicas no Brasil. In: DAGninO, E. (Org.). 2002. Sociedade Civil e Espaços Públicos no Brasil. São Paulo: Paz e Terra, 2002. 